\title{
Treatment choices for newly diagnosed primary open angle and ocular hypertension patients
}

\author{
Anurag Garg ${ }^{1} \cdot$ Gus Gazzard ${ }^{1}$
}

Received: 28 June 2019 / Revised: 4 September 2019 / Accepted: 11 September 2019 / Published online: 4 November 2019

(c) The Author(s), under exclusive licence to The Royal College of Ophthalmologists 2019

\begin{abstract}
Despite advances in our knowledge of the aetiology and pathophysiology of glaucoma, the sole proven, effective intervention for treating primary open-angle glaucoma (POAG) and ocular hypertension (OHT) remains lowering of intraocular pressure (IOP) to prevent further progression and visual loss. The purpose of this review is to evaluate the treatment choices available to newly diagnosed POAG and OHT patients. We review the existing literature on treatments currently available to newly diagnosed POAG and OHT patients and discuss their role in the treatment paradigm of POAG and OHT. We consider different factors that may be important when offering a choice of treatment to newly diagnosed POAG and OHT patients as well as describing new glaucoma treatments in development and future directions for treatment.
\end{abstract}

\section{Introduction}

Glaucoma is a progressive multifactorial disease characterised by damage to the optic nerve. It is the second leading cause of blindness worldwide and it is predicted by 2020, close to 80 million people will have the disease, the majority affected by primary open-angle glaucoma (POAG) [1]. POAG is strongly associated with elevated intraocular pressure (IOP) but may also occur with IOP in the normal range. Certain individuals can have elevated IOP without detectable glaucomatous damage. These individuals are at an increased risk of developing POAG and are referred to as having ocular hypertension (OHT).

Despite advances into our knowledge of the aetiology and pathophysiology of POAG, the current mainstay of glaucoma treatment remains lowering of IOP to prevent further progression and visual loss. In this review, we discuss different factors that may be important to consider when offering a choice of treatment to newly diagnosed POAG and OHT patients and describe new glaucoma

Gus Gazzard

gusgazzard@gmail.com

1 NIHR Biomedical Research Centre at Moorfields Eye Hospital NHS Foundation Trust and UCL Institute of Ophthalmology, London, UK treatments in development and future directions for POAG and OHT treatment.

\section{Aims of treatment}

The aim of glaucoma treatment is to slow or stop disease progression and preserve patients' vision-related quality of life for the duration of their lifetime.

IOP is the sole modifiable risk factor proven to alter the disease course in glaucoma [2]. Several clinical trials have demonstrated the benefit of IOP lowering in preventing the development of POAG and slowing disease progression.

The Ocular Hypertension Treatment Study (OHTS) [3] randomised patients with OHT to treatment vs. no treatment. At the end of 5 years follow-up, $4.4 \%$ of patients in the medication group vs. $9.5 \%$ in the untreated group developed signs of glaucoma. The Early Manifest Glaucoma Trial (EMGT) [4] randomised early POAG patients to treatment (laser trabeculoplasty + topical beta blocker) vs. no treatment. After a median follow-up of 6 years, progression was less frequent in the treatment group (45\%) compared to in the control group (62\%). More recently, the United Kingdom Glaucoma Treatment Study (UKGTS) demonstrated that POAG patients treated with IOPlowering medication were less likely to demonstrate visual field progression at 24 months compared to those treated with placebo (hazard ratio $0.44 ; 95 \%$ confidence interval, $0.28-0.69 ; p=0.0003)$, confirming that IOP 
lowering was associated with alteration of the disease course and reduced visual field progression [2]. Furthermore, these studies demonstrated that the degree of IOP lowering influences disease progression. The EMGT study estimated that each $1 \mathrm{mmHg}$ reduction in IOP reduced the risk of disease progression by $\sim 10 \%$ [5].

IOP lowering has also been shown to be effective in delaying disease progression in glaucoma patients without elevated IOP, a condition known as normal tension glaucoma (NTG). In the Collaborative Normal Tension Glaucoma Study (CNTG), 140 patients with NTG received IOPlowering medical or surgical treatment in one eye. At the study endpoint, there was a slower rate of incident visual field loss in cases that achieved IOP lowering of $30 \%$ or more from baseline IOP compared to untreated fellow eyes [6].

Current management strategies recommend IOP lowering towards a target IOP, where the rate of disease progression is slowed sufficiently to avoid functional impairment from the disease [7]. Target IOP for an individual eye is established from pre-treatment IOP levels, the severity of visual field loss, risk factors for progression, life expectancy and potential for adverse effects from treatment [8]. In general, the initial target IOP aims for a $20-50 \%$ reduction from baseline IOP. This must be continuously reevaluated however during follow-up and adjusted depending on treatment effect and disease progression.

Despite IOP lowering being the mainstay of POAG/OHT treatment, IOP is not the only risk factor for OHT and POAG disease progression. Optic nerve damage and visual field loss can still occur in spite of normal IOP or previous IOP lowering. This is evident from NTG patients, as well as eyes that demonstrate disease progression (visual field loss or disc damage) while at target IOPs. Several risk factors associated with POAG have already been identified, including age, ethnicity, family history, thinner central corneal thickness and myopia [9]. The exact mechanism of how some of these factors are associated with disease pathogenesis is still to be fully determined, but with increasing evidence that POAG may not solely be an IOPrelated disease, greater research into alternative/adjunctive treatment strategies for POAG (unrelated to IOP lowering) such as neuroprotection is also taking place [10].

\section{Factors to consider in choice of treatment}

IOP lowering can be achieved by medication, laser or surgery (either alone or in combination). Prior to initiating any treatment, it is imperative that the treating clinician and patient discuss in detail the relative risks and benefits of the treatment being offered such that the patient is fully informed. Several factors need to be evaluated when considering potential treatment options.
The clinician may need to consider patient-related disease-specific factors, including glaucoma severity (degree of visual field loss, severity of visual field loss, one eye vs. two eye involvement), degree of IOP lowering required, as well as evaluate what treatments (if any) have been utilised and been effective until that point. The patients' concurrent systemic co-morbidities (e.g. asthma, chronic obstructive pulmonary disease (COPD), cardiac arrhythmias) and allergies or intolerances should also be considered, as these may limit the use of certain treatments, e.g. the relative contra-indication of topical beta blocker usage in asthma or COPD patients. By utilising both their own clinical experience and consulting the relevant scientific literature or clinical guidelines pertinent to the patient's disease, the clinician can then tailor the treatment discussion and make recommendations appropriately using an evidence-based medicine approach [11].

The patients' own awareness of their condition and their treatment preferences should also be explored and established, such that the decision to opt for a specific treatment is a joint one between clinician and patient. A family history of glaucoma and its severity may also shed light on the likely outcome, but is essential to explore for the impact it inevitably has on a patient's fears and expectations. Patient education and informed participation in treatment decisions has been shown to improve treatment compliance [12]. This is particularly crucial for effective management of glaucoma, since it is a chronic and progressive disease requiring lifelong monitoring (i.e. regular clinical attendance) and treatment (i.e. regular instillation of topical medication if indicated). Socio-economic factors can also influence treatment compliance. Studies from the USA have shown disparities in utilisation of eye care services among different racial minorities. Socio-economic deprivation and differences in access to healthcare have been implicated as contributory to this $[13,14]$. The likelihood of patient compliance to a particular treatment plan needs to be thus carefully judged, with appropriate adjustment if required.

Clinicians may also increasingly consider patient reported outcome measures (PROMs) of different treatments as part of any treatment decision-making process. Greater emphasis on patient-centred care in glaucoma has led to the increasing utilisation of PROMs in glaucoma research [15-17]. PROMS are a series of standardised and validated questions that are self-reported by patients to assess their own perspective on the impact of the disease and treatment on their own health status, health-related quality of life (HRQL) and functioning [18]. This information is important to clinicians as it provides feedback on the care provided and can also be used to assess patient judged effectiveness of different treatments.

A final consideration in treatment choice is treatment cost. Treatment of glaucoma and OHT imposes a significant cost burden on healthcare systems [19] and availability of certain 
treatment modalities in different healthcare settings may be influenced by cost. Studies have used various economic modelling techniques to compare costs of different treatment modalities against one another. Several have demonstrated the cost benefit of laser trabeculoplasty as a primary treatment for glaucoma compared to conventional medical treatment in different healthcare settings [17, 19-22]. Within a United Kingdom (UK) National Health System (NHS) setting, a recent study has demonstrated the cost-effectiveness of using primary selective laser trabeculoplasty (SLT) in treatment-naive OAG or OHT patients vs. topical medication at 36 months [17]. Cantor et al. [23] used Markov modelling to compare the treatment costs of uncontrolled glaucoma treated with either further medications, SLT followed by further medications or surgery. They found the 5-year cumulative costs per patient were $\$ 6571, \$ 4838$ and $\$ 6363$ in the medication, SLT and surgery arms, respectively. Other studies have modelled the cost-effectiveness of surgical interventions, including trabeculectomy or tube surgery vs. medication [24] and MIGS procedures vs. medication or SLT $[25,26]$.

\section{Choice of treatment}

As described previously, IOP lowering can be achieved by medication, laser or surgery (either alone or in combination).

\section{Medication}

Topical IOP-lowering medications have long been the primary POAG treatment and widely used, with $\sim 1.2$ million prescriptions being issued per month in the UK [27].

Several classes of medication are used to lower IOP in glaucoma. The prostaglandin analogues reduce IOP by increasing the outflow of aqueous humour, primarily through the uveoscleral pathway [28]. They have also been shown to activate matrix metalloproteinases (MMPs), which remodel extracellular matrix within the trabecular meshwork (TM) and reduce outflow resistance, allowing the aqueous humour to flow out via this route [29]. In general, prostaglandins became the first-line of medical treatment because of their IOP-lowering efficacy, once daily application and minimal systemic side-effects. Prostaglandins have been reported to achieve between 25-33\% IOP reduction from baseline IOP [30]. In a systematic review comparing the effectiveness of different first-line medications for POAG, prostaglandins were found to be the most efficacious in terms of mean IOP reduction $(95 \%$ credible intervals) at 3 months (bimatoprost $5.61 \mathrm{mmHg}$ (4.94, 6.29); latanoprost $4.85 \mathrm{mmHg}(4.24,5.46)$; travoprost 4.83 $\mathrm{mmHg}(4.12,5.54)$ [31]. Ocular side-effects include gradual irreversible darkening of the iris in a small percentage of patients due to an increase in melanosomes [32]. Other sideeffects include increased growth and hyperpigmentation of eyelashes, conjunctival hyperaemia, loss of periorbital fat and periocular skin pigmentation [8].

Beta blockers are also widely used and reduce aqueous humour secretion. They can achieve between 20-25\% IOP reduction from baseline IOP [30] and have been shown to be slightly inferior to prostaglandins in terms of mean IOP reduction at 3 months [31]. They can cause systemic cardiovascular (bradycardia, hypotension) and respiratory sideeffects (bronchospasm), especially in the elderly [33], as well as other side-effects such as depression, nightmares, impotence, loss of libido and reduced exercise tolerance. Consequently, they have to be used with care and their use may be limited in patients with asthma or COPD.

Carbonic anhydrase inhibitors reduce aqueous secretion and are used in both topical and oral forms in the treatment of glaucoma. They can achieve between 15-30\% IOP reduction from baseline IOP, with the oral form (e.g. acetazolamide) being more effective at IOP lowering than topical forms (e.g. dorzolamide, brinzolamide) but also being associated with the risk of greater systemic sideeffects [30]. Potential systemic side-effects of oral carbonic anhydrase inhibitors include depression, anorexia, gastrointestinal disturbance, paraesthesia, kidney stones and serum electrolyte disturbance. Patients with pre-existing renal impairment, blood dyscrasias (e.g. sickle cell disease, thrombocytopenia, aplastic anaemia), kidney stones and sulphonamide allergy may have a relative contra-indication to oral carbonic anhydrase inhibitor use and care must be taken in such patients [30].

The $\alpha 2$ adrenergic agonists reduce secretion of aqueous humour initially and then primarily increase aqueous outflow [34]. They can achieve 20-25\% IOP reduction from baseline IOP [30]. Topical $\alpha 2$ adrenergic agonists are associated with allergic conjunctivitis, can cause sedation, and have the potential for systemic sympathomimetic activity.

Cholinergic agonists (e.g. pilocarpine) increase aqueous outflow through the TM and can achieve between 20-25\% IOP reduction from baseline [30]. They can have substantial ocular side-effects, in particular blurring of vision due to the small pupil and induced myopia, which now largely restrict their use to short-term and very limited situations.

While a single topical medication may be adequate in the initial stages of treatment for a newly diagnosed POAG or OHT patient, frequently, a combination of topical medications may eventually be required. This may take the form of a medication switch (to an alternate class of medication) or the addition of further medication to a pre-existing treatment regime and could be due to a multitude of reasons, including side effect intolerance, inability to achieve target IOP or need to for greater IOP lowering. In a previous 
retrospective analysis of 16,486 glaucoma patients using a prostaglandin, $\sim 30 \%$ required adjunctive medication within 12 months [35]. Fixed combinations of IOP-lowering medications have been shown to be more effective than monotherapy with the individual components in terms of IOP lowering, while offering the potential advantages of enhanced convenience, improved adherence, reduced exposure to preservatives and possible lower cost [36]. A possible disadvantage of fixed combination medications is that there is no option for adjusting the strength of individual medications within the combination and the IOP lowering of fixed combinations is often less than if the two combined medications were given together but separately in accordance with their individual dosing schedules [37].

While topical medications are effective, there are several potential pitfalls associated with their use. As already discussed, a significant proportion of patients require more than one type of drop, with a third of patients in the UK using more than one medication. In addition, as glaucoma is a chronic and progressive disease, instillation of medication becomes a lifelong commitment, with patient compliance therefore becoming essential for successful management. Studies show however that patient compliance with topical medication can be variable [38, 39], with reported noncompliance rates ranging from 24 to $80 \%$ depending on definition [38-41] and up to half of patients started on glaucoma treatment discontinuing eye-drops by 6 months in one study [42].

There are several reasons for potential poor compliance. Drops are expensive, with side-effects that limit acceptability and impair HRQL [43]. Long-term topical medications are often associated with pain on instillation and can cause multiple ocular and systemic side-effects. Their use requires regular monitoring and frequent adjustment, with $\sim 22 \%$ of changes to drop regimes being due to adverse reactions [44]. In addition, glaucoma patients are frequently elderly and may have other co-morbidities which may reduce their ability to take medication, such as diminished cognition, poor hearing and arthritis of their hands. Longterm drop use has also been shown to be a strong risk factor for later surgical treatment failure, due to conjunctival fibroblast activation by medications or preservatives $[45,46]$.

\section{Medications in development}

Newer medical treatments are in development. Most of these are IOP-lowering treatments with new mechanisms of action, better efficacy, tolerability and convenience.

Trabodenoson is a highly selective adenosine-1 receptor agonist. It upregulates MMP-2 expression in the TM, resulting in remodelling of the extracellular matrix, thus lowering outflow resistance and enhancing aqueous humour outflow [47]. In a phase 2 randomised controlled trial (RCT), topical trabodenoson was compared against placebo and achieved a mean reduction of $4.1 \mathrm{mmHg}$ from baseline while being well-tolerated [48]. However, in a phase 3 trial vs. placebo, there was no significant difference in IOP lowering between groups.

Netarsudil is a Rho-kinase (ROCK) inhibitor and norepinephrine transporter inhibitor [49]. It has been shown to cause IOP lowering through several mechanisms. Primarily, it causes relaxation within the TM and contraction of the ciliary muscle, leading to an increase in aqueous humour outflow through the TM [50]. It also decreases aqueous production and decreases episcleral venous pressure $[51,52]$. Different studies have assessed its efficacy alone [53] and in combination with existing medications such as latanoprost [54]. Despite a short follow-up duration, they have demonstrated non-inferiority to currently available treatments but side-effects such as conjunctival hyperaemia in a high proportion of patients has been noted.

Latanoprostene Bunod (LBN) is a modified prostaglandin analogue which has a dual mechanism of action. Upon topical administration into the eye, it is hydrolysed by endogenous esterases into latanoprost acid, the active component of latanoprost, and butanediol mononitrate, which breaks down into nitric oxide (NO) and inactive 1,4butanediol [55]. Latanoprost acid increases aqueous outflow through the uveoscleral pathway [28], while NO causes relaxation within the TM and increases aqueous outflow through the TM and Schlemm's canal [56]. Several phase 3 studies have evaluated LBN [57-59] and found it to be more effective at IOP lowering than topical beta blocker at 3 months while maintaining a similar safety profile to other prostaglandin analogues.

\section{Laser}

Laser trabeculoplasty (LT) is a laser treatment modality, which reduces IOP and is increasingly being used worldwide. Argon laser trabeculoplasty (ALT) was the first version of LT developed in 1979 [60]. IOP reduction was mediated by an increase in aqueous outflow, confirmed by both tonographic and aqueous dynamic studies [61, 62]. Subsequently, selective laser trabeculoplasty (SLT), which uses much lower energy exposures with minimal permanent tissue damage has superseded ALT to become the principal laser treatment modality for IOP lowering.

First introduced by Latina \& Park in 1995, SLT uses a $532 \mathrm{~nm}$ Q switched, frequency doubled Nd:YAG laser that is able to deliver a short laser pulse duration $(3 \mathrm{~ns})$. It satisfies the dual criteria required for selective photothermolysis, preventing heat dissipation outside of pigmented TM cells and thus causing less collateral damage 
compared to ALT as a result [63]. Similar to ALT, SLT has been demonstrated by tonographic and aqueous dynamic studies to increase aqueous outflow through the TM [6466], mediated by changes in gene expression, cytokine secretion, matrix metalloproteinase induction and TM remodelling [67-70]. Importantly, SLT does not cause the same level of structural damage as ALT. Histopathological comparisons of human eyes that have undergone ALT vs. SLT have shown lesser damage to the TM in SLT eyes, with no evidence of coagulative damage or disruption of the corneoscleral or uveal trabecular beam structure [71].

Since SLT received FDA approval in 2001, it has increasingly been adopted into clinical practice [72]. The clinical benefits are clear; the procedure is quick, outpatient based with minimal recovery time and a good safety profile. In addition, SLT avoids the multitude of side-effects and compliance issues associated with topical medication.

SLT has been investigated in various clinical scenarios ranging from as a primary treatment in newly diagnosed POAG/OHT patients [17, 73-76], to as an adjunctive treatment in patients on concurrent medical therapy [77, 78]. Most studies investigating IOP lowering using SLT in newly diagnosed POAG/OHT patients have done so by comparing its efficacy against topical medication [79]. Nagar et al. [80] performed a RCT where 40 newly diagnosed $\mathrm{OHT}$ or POAG patients were randomised to receive either $360^{\circ} \mathrm{SLT}$ or $0.005 \%$ latanoprost. SLT was found to decrease IOP by $4.7 \mathrm{mmHg}$ on average (95\% CI, 3.6 to 5.7 $\mathrm{mmHg} ; p<0.01)$ with a similar reduction achieved from latanoprost. There was no difference in treatment success at last follow-up (4-6 months) between groups $(p=0.4)$ and both were found to reduce daily IOP fluctuation. A different study by the same group demonstrated that IOP lowering and success rates were equivalent between $360^{\circ}$ SLT and latanoprost treatment groups, but not $90^{\circ}$ and $180^{\circ} \mathrm{SLT}$ treatment groups [74]. In a meta-analysis of four RCTs and one prospective non-randomised trial comparing SLT with medication [81], evaluation of IOP reduction showed no significant difference in IOP reduction compared to medication (weighted mean difference $0.6 \mathrm{mmHg}, 95 \% \mathrm{CI}$, -0.24 to $1.43 \mathrm{mmHg}$ ). In a comparison of the proportion of patients achieving target endpoint IOP at follow-up endpoint, the difference in success rates between the SLT group and medication group was also not statistically significant (pooled OR $0.84,95 \%$ CI, 0.42 to 1.68 ).

Since SLT causes minimal structural TM damage, repeat SLT treatment has also been studied and considered feasible in suitable patients requiring further IOP reduction [82-88]. With regard to safety and tolerability, SLT has been shown to be relatively safe and well-tolerated with low complication rates [89]. Most of the complications associated with SLT are transient and self-limiting. These include anterior chamber inflammation [89], IOP spikes [90], transient corneal endothelial changes or stromal haze [91, 92] and retinal changes, including cystoid macular oedema [93-95], development of subretinal fluid [96] and post SLT choroidal effusions [97, 98]. Unlike ALT, the development of peripheral anterior synechiae (PAS) is not common post SLT. In their meta-analysis, Wong et al described only $2.86 \%$ of cases developed PAS [99] though it has been described to occur after repeat SLT [100].

Direct comparison between SLT studies is difficult. Differences in study design, patient demographics, disease subtypes being investigated (OHT vs. POAG), usage of topical IOP-lowering medication prior to SLT (treatmentnaive vs. medication washout prior to SLT vs. concurrent topical medication), SLT treatment parameters (180 degree vs. 360 degree treatments, variability in numbers of shots fired), follow-up intervals, total duration of follow-up and definitions of success all mean that comparison between studies is a challenge. In some studies, patients included in the SLT arm were taking topical medications that were stopped for a variable duration (4 weeks to 3 months) prior to receiving SLT $[74,75,101]$ and so were not truly treatment-naive prior to receiving SLT. Despite a washout period, to mitigate against residual effects of prior topical treatment, studies have shown SLT to be less effective when used following topical treatment [75].

A previous Cochrane systematic review has highlighted the need for further research to compare the clinical efficacy and cost-effectiveness of SLT to topical medication for the treatment of open-angle glaucoma or ocular hypertension [102].

Recently, the Laser in Glaucoma and Ocular Hypertension (LiGHT) study [17], an observer-masked, multi-centre randomised controlled trial has evaluated treatment-naive patients with open-angle glaucoma or ocular hypertension randomly allocated to receive either initial primary SLT or initial topical medication. Eyes were treated to individualised objective target IOPs set according to glaucoma severity, while treatment decisions were guided by a robust treatment escalation protocol to capture realistic clinical management while minimising risk of bias. The primary outcome was HRQL at 3 years (assessed by EQ5D). Secondary outcomes were cost-effectiveness, disease-specific HRQL, clinical effectiveness and safety. Of 718 patients enrolled, 356 were randomised to primary SLT and 362 to initial topical medication. $652(91 \%)$ returned the primary outcome questionnaire at 36 months. Average EQ5D score was 0.89 (SD 0.18) in the SLT group vs. 0.90 (SD 0.16) in the topical medication group, with no significant difference noted between groups at 36 months (adjusted mean difference $0.01,95 \% \mathrm{CI}-0.01$ to $0.03 ; p=0.23$ ). At 36 months, $74.2 \%$ (95\% CI 69.3-78.6) of patients in the SLT group required no drops to maintain IOP at target. Eyes of patients in the SLT group were within target IOP at more visits 
$(93.0 \%)$ than in the topical medication group $(91.3 \%)$, with glaucoma surgery to lower intraocular pressure required in none vs. 11 patients. Over 36 months, from an ophthalmology cost perspective, there was a $97 \%$ probability of SLT as an initial treatment being more cost-effective than initial topical treatment at a willingness to pay of $£ 20000$ per quality-adjusted life-year gained.

The LiGHT study demonstrates that there is no difference in HRQL between primary SLT and initial topical medication at 36 months. SLT is safe and effective as a firstline treatment for open-angle glaucoma and ocular hypertension and should be offered as an alternative to IOPlowering topical medication. It provides good IOP control, at a lower cost and allowed almost three quarters of patients (74\%) to be successfully controlled without drops for at least 3 years after starting treatment.

\section{Lasers in development}

Other laser trabeculoplasty procedures include Micropulse Diode Laser Trabeculoplasty (MDMT), Titanium Sapphire Laser Trabeculoplasty (TLT) and Pattern Scanning Laser Trabeculoplasty (PSLT). While some small studies have compared their efficacy against SLT and found potential advantages, larger studies are required to establish whether any of these newer treatment modalities offer any advantage over existing SLT treatments. All use higher energy exposures with the attendant risks of permanent meshwork damage and potential less scope for retreatment.

Micropulse diode laser trabeculoplasty (MDLT) uses sub-visible (subthreshold) applications of repetitive short diode $(532,577$ or $810 \mathrm{~nm}$ ) laser pulses spaced by a long relaxation time with a spot size of 300 microns. While MDLT apparently does not cause coagulative damage to the trabecular meshwork [103] and there is no blanching or bubble formation over the TM during the treatment, limited data exists. Post treatment inflammation is minimal hence no anti-inflammatory medications are required. MDLT results are variable_-some studies reporting limited IOP lowering success [104] while others reporting mean IOP reduction between $19.5-22 \%$ with a good safety profile $[105,106]$. In a comparison with SLT, the percentage of eyes achieving IOP reduction $>20 \%$ from baseline was similar between MDLT and SLT [107].

TLT uses near infrared energy $(790 \mathrm{~nm})$ in short pulses (5-10 ms) with a spot size of 200 microns. The near infrared wavelength is believed to penetrate deeper ( 200 microns) to the inner and outer walls of Schlemm's canal, as well as the collector channels and ciliary body. The laser is believed to be selectively absorbed by pigmented phagocytic cells, preserving TM tissue [108]. The total radiation energy of TLT is 250 times that of SLT but is delivered over a longer time period, resulting in a longer thermal relaxation time, causing minimal collateral coagulative damage as a result [109]. In a small RCT comparing TLT vs. SLT in OAG/ OHT patients, no statistically significant differences in IOP reduction or success rates were noted between groups. Treatments had a similar adverse events profile but despite this, some concerns remain about the long burn duration and deeper penetration of TLT compared to SLT [109].

PSLT uses short pulse durations (10-20 ms), 100 micron spot size and computer guided predetermined pattern of spots. This results in reduction of thermal diffusion and surrounding tissue damage while permitting many more shots to be applied per area of TM [103]. In a recent RCT [110], the safety, tolerability and IOP-lowering efficacy of PSLT was compared against SLT. Twenty-nine OAG patients underwent PSLT in one eye and SLT in the fellow eye. There was no significant difference in mean IOP reduction at latest follow-up (6 months).

Trans-scleral or Direct SLT allows $360^{\circ}$ treatment around the perilimbal sclera overlying the TM without a gonioscopy lens. This eliminates corneal and gonioscopyrelated side-effects $[111,112]$. It utilises similar laser settings to conventional SLT and has similar IOP-lowering efficacy but shots are fired simultaneously in $<1$ second reducing procedure duration.

\section{Surgery}

Several different glaucoma IOP-lowering surgeries existpenetrating (e.g. trabeculectomy, tube surgery) vs. nonpenetrating surgery (e.g. deep sclerectomy, visco-canalostomy, canaloplasty). Their use in clinical practice is a combination of surgeon preference (having considered the IOP-lowering evidence and safety profile of each procedure) and patient factors. Cataract surgery also has an IOPlowering effect [113] and so clinicians may consider phacoemulsification as a valid surgical treatment option for newly diagnosed POAG or OHT patients with visually significant cataracts, who also require further IOP lowering.

Incisional glaucoma surgery generally achieves greater IOP lowering compared to topical medication [114] and is usually performed if IOP lowering is insufficient following topical medication or laser. However, in newly diagnosed OHT and POAG patients, it may be a viable first option in those with poor compliance or intolerant to medication. The Treatment of Advanced Glaucoma Study (TAGS) is currently investigating whether surgical intervention could be the most favourable treatment option in newly diagnosed POAG patients with advanced disease; by comparing effectiveness of medical treatment against augmented trabeculectomy in patients presenting with advanced glaucoma in terms of patient reported health and visual function, clinical outcomes and cost-effectiveness at 24 months [115]. 


\section{Penetrating glaucoma surgery}

Trabeculectomy remains the most common initial operation for patients with advanced glaucoma in most countries [8]. Trabeculectomy lowers IOP by creating a new drainage site for aqueous humour outflow underneath the conjunctiva [116]. Glaucoma drainage device, or tube surgery, has traditionally been reserved to treat patients with refractory cases of glaucoma or at high risk of failure. The two most commonly used glaucoma drainage implants are the Ahmed valve (New World Medical, Rancho Cucamonga, CA) and the Baerveldt implant (Abbott Medical Optics, Santa Ana, CA).

The Tube vs. Trabeculectomy (TVT) study selected patients who had previous trabeculectomy and/or cataract extraction with uncontrolled glaucoma on maximal medical therapy and randomised them to either Baerveldt $350 \mathrm{~mm}^{2}$ implant or repeat trabeculectomy with mitomycin $\mathrm{C}$ (MMC). At 5 years post-operatively, the cumulative probability of failure was $29.8 \%$ in the tube group vs. $46.8 \%$ in the trabeculectomy group (hazard ratio $=2.15,95 \% \mathrm{CI}$, 1.30 to $3.56 ; p=0.02$ ). Furthermore, the rate of reoperation was significantly greater in the trabeculectomy group (29\%) vs. tube group (9\%) $(p=0.025)$ [117]. The Primary Tube vs. Trabeculectomy (PTVT) study is evaluating the effectiveness of tube surgery vs. trabeculectomy with MMC in medically uncontrolled glaucoma patients who have not undergone previous incisional ocular surgery [118]. Early 12-month clinical outcomes demonstrate trabeculectomy has a higher surgical success rate than tube surgery. Trabeculectomy achieved lower IOP with use of fewer glaucoma medications compared with tube surgery, but there was also a higher incidence of serious complications.

Other studies have evaluated the efficacy and safety between the two most common glaucoma drainage devices. The Ahmed Baerveldt Comparison ('ABC') Study was a prospective randomised study in which patients with previous intraocular surgery or refractory glaucoma and IOP > $18 \mathrm{mmHg}$ were randomised to either implantation of the Ahmed FP7 valve or the Baerveldt 101-350 device. At 5 years follow-up, there were similar rates of surgical success between the two devices (cumulative probability of failure: Ahmed group 44.7\% vs. Baerveldt group 39.4\%; $p=0.65$ ). Baerveldt implantation produced a greater IOP reduction and a lower rate of glaucoma reoperation, but was also associated with twice as many failures due to safety issues such as persistent hypotony, loss of light perception or explantation [119].

\section{Non-penetrating glaucoma surgery}

The principle of non-penetrating glaucoma surgery is to create filtration through a naturally occurring membrane, the trabeculo-Descemet's membrane (TDM), which provides resistance to outflow. There is no penetration into the anterior chamber as a sclerostomy is not created. Two main techniques are described-deep sclerectomy and visco-canalostomy. Studies have demonstrated the IOP lowering is generally greater with trabeculectomy, however the main benefit of non-penetrating glaucoma surgery is the lower complication profile compared to trabeculectomy [120-122]. The main disadvantage of non-penetrating glaucoma surgery techniques is that they are associated with a long and demanding learning curve with fewer surgeons performing them as a result.

\section{Minimally invasive glaucoma surgery}

Newer procedures and devices are emerging to lower IOP with a greater safety profile compared to incisional glaucoma surgery and these are collectively termed 'Minimally Invasive Glaucoma Surgery' (MIGS). MIGS procedures are commonly performed alongside cataract surgery. MIGS devices aim to lower IOP by increasing aqueous outflow through existing anatomical outflow pathways including through the TM into Schlemm's canal [123, 124], through the uveoscleral pathway [125], as well as through alternate pathways, which are created iatrogenically such as subconjunctivally [126]. The main advantage of MIGS is that most devices are nonpenetrating and/or bleb-independent procedures, thus avoiding the major complications of fistulating surgery related to blebs and hypotony. The degree of IOP lowering, however, is generally accepted to be less than that achieved by trabeculectomy or tube surgery. RCTs comparing IOP lowering between combined surgery (cataract surgery + MIGS) vs. cataract surgery alone have demonstrated that in a combined procedure, cataract surgery achieves the majority of IOP lowering with an additional modest (but statistically significant) lowering of IOP achieved by the MIGS device [113, 124, 125]. A reduction in the number of topical IOP-lowering medications required by patients post-operatively is a potential benefit. Whether the additional IOP lowering is clinically beneficial in terms of preventing long-term disease progression, while also taking into account the extra cost of the device, is still to be determined. Moreover, limited long-term follow-up data exists for the majority of MIGS devices. A recent long-term followup safety study of a MIGS device (CyPass Micro-Stent; Transcend Medical, Inc., Menlo Park, CA) has demonstrated unacceptable endothelial cell count loss over 5 years, leading to its' withdrawal. While the exact role of MIGS is yet to be established, it may be that MIGS procedures will exist alongside rather than replacing more invasive IOP-lowering surgical options. They 
may be used in early or moderate POAG patients where lesser degrees of IOP lowering are acceptable and as a means of postponing more invasive surgical interventions [127].

\section{Neuroprotection}

Neuroprotection is the term used for therapies that are independent of IOP lowering and aim to protect retinal ganglion cells (RGCs) from axonal injury and slow functional loss. Studies using animal models of glaucoma have demonstrated success of various different neuroprotective treatments to preserve RGCs and their function [128], however, this success has not translated into human clinical trials thus far. Several reasons have been purported for translational failure [129]. While some solutions to address these have been suggested [128], translation of laboratory results to clinical trials in glaucoma remains limited and as yet, there are still no reliably proven neuroprotective treatments related to glaucoma that are available to humans currently.

\section{Which treatment to choose?}

As outlined in this manuscript, the choice of treatment for a newly diagnosed POAG or OHT patient is based on a multifactorial decision-making process. It requires input from both the patient and the treating clinician and should be individually tailored to the patient. Different worldwide treatment recommendations and guidelines exist for the management of POAG and OHT [30, 130-132], which the treating clinician can consult alongside using their own clinical experience. The risks and benefits of each treatment should be considered and discussed with the patient such that an informed decision can be made.

\section{Conclusions}

There are multiple treatment choices available for newly diagnosed POAG or OHT patients. The decision on which to choose is multifactorial, requiring input from both the patient and the treating clinician. Treatment should be individually tailored to the patient and the relevant risks and benefits should be considered and discussed prior to initiation such that an informed decision can be made. Newer treatments are in constant development, including the concept of neuroprotection, though currently, IOP lowering looks to remain the mainstay of glaucoma and OHT management for the foreseeable future.
Funding The authors have received financial research support that contributes to their ongoing research work from the following organisations: Anurag Garg: Fight For Sight Charity; International Glaucoma Association/Royal College of Ophthalmologists. Gus Gazzard: National Institute for Health Research, Health and Technology Assessment Programme; Moorfields Eye Charity; BCPB.

\section{Compliance with ethical standards}

Conflict of interest The authors declare that they have no conflict of interest.

Publisher's note Springer Nature remains neutral with regard to jurisdictional claims in published maps and institutional affiliations.

\section{References}

1. Quigley HA, Broman AT. The number of people with glaucoma worldwide in 2010 and 2020. Br J Ophthalmol. 2006;90:262-7.

2. Garway-Heath DF, Crabb DP, Bunce C, Lascaratos G, Amalfitano F, Anand N, et al. Latanoprost for open-angle glaucoma (UKGTS): a randomised, multicentre, placebo-controlled trial. Lancet (Lond, Engl). 2015;385:1295-304.

3. Kass MA, Heuer DK, Higginbotham EJ, Johnson CA, Keltner JL, Miller JP, et al. The Ocular Hypertension Treatment Study: a randomized trial determines that topical ocular hypotensive medication delays or prevents the onset of primary open-angle glaucoma. Arch Ophthalmol (Chic, Ill : 1960). 2002;120:701-13.

4. Heijl A, Leske MC, Bengtsson B, Hyman L, Bengtsson B, Hussein M. Reduction of intraocular pressure and glaucoma progression: results from the Early Manifest Glaucoma Trial. Arch Ophthalmol (Chic, Ill : 1960). 2002;120:1268-79.

5. Leske MC, Heijl A, Hussein M, Bengtsson B, Hyman L, Komaroff E. Factors for glaucoma progression and the effect of treatment: the early manifest glaucoma trial. Arch Ophthalmol (Chic, Ill : 1960). 2003;121:48-56.

6. Collaborative Normal-Tension Glaucoma Study Group. Comparison of glaucomatous progression between untreated patients with normal-tension glaucoma and patients with therapeutically reduced intraocular pressures. Am J Ophthalmol. 1998;126:487-97.

7. Damji KF, Behki R, Wang L. Canadian perspectives in glaucoma management: setting target intraocular pressure range. Can J Ophthalmol J Canadien d'ophtalmologie. 2003;38:189-97.

8. Weinreb RN, Aung T, Medeiros FA. The pathophysiology and treatment of glaucoma: a review. JAMA. 2014;311:1901-11.

9. Weinreb RN, Khaw PT. Primary open-angle glaucoma. Lancet. 363:1711-20.

10. Pietrucha-Dutczak M, Amadio M, Govoni S, Lewin-Kowalik J, Smedowski A. The role of endogenous neuroprotective mechanisms in the prevention of retinal ganglion cells degeneration. Front Neurosci. 2018;12:834.

11. Sackett DL, Rosenberg WM, Gray JA, Haynes RB, Richardson WS. Evidence based medicine: what it is and what it isn't. BMJ (Clin Res ed). 1996;312:71-2.

12. Osterberg L, Blaschke T. Adherence to medication. New Engl J Med. 2005;353:487-97.

13. Wang F, Javitt JC, Tielsch JM. Racial variations in treatment for glaucoma and cataract among Medicare recipients. Ophthalmic Epidemiol. 1997;4:89-100.

14. Stein JD, Talwar N, Laverne AM, Nan B, Lichter PR. Racial disparities in the use of ancillary testing to evaluate individuals 
with open-angle glaucoma. Arch Ophthalmol (Chic, Ill : 1960). 2012;130:1579-88.

15. Jones L, Garway-Heath DF, Azuara-Blanco A, Crabb DP. Are patient self-reported outcome measures sensitive enough to be used as end points in clinical trials?: evidence from the United Kingdom Glaucoma Treatment Study. Ophthalmology. 2019;126:682-89.

16. Azuara-Blanco A, Burr J, Ramsay C, Cooper D, Foster PJ, Friedman DS, et al. Effectiveness of early lens extraction for the treatment of primary angle-closure glaucoma (EAGLE): a randomised controlled trial. Lancet (Lond, Engl). 2016;388:1389-97.

17. Gazzard G, Konstantakopoulou E, Garway-Heath D, Garg A, Vickerstaff V, Hunter R, et al. Selective laser trabeculoplasty versus eye drops for first-line treatment of ocular hypertension and glaucoma (LiGHT): a multicentre randomised controlled trial. Lancet. (London, England). 2019;393:1505-16.

18. Hee OK, Thng ZX, Zhu HY, Lamoureux EL. Usage of glaucoma-specific patient-reported outcome measures (PROMs) in the Singapore context: a qualitative scoping exercise. BMC Ophthalmol. 2018;18:197.

19. Dirani M, Crowston JG, Taylor PS, Moore PT, Rogers S, Pezzullo ML, et al. Economic impact of primary open-angle glaucoma in Australia. Clin Exp Ophthalmol. 2011;39:623-32.

20. Taylor HR. Glaucoma: where to now? Ophthalmology. 2009;116:821-2.

21. Lee R, Hutnik CM. Projected cost comparison of selective laser trabeculoplasty versus glaucoma medication in the Ontario Health Insurance Plan. Can J Ophthalmol J Canadien d'ophtalmologie. 2006;41:449-56.

22. Guedes RA, Guedes VM, Gomes CE, Chaoubah A. Maximizing cost-effectiveness by adjusting treatment strategy according to glaucoma severity. Medicine. 2016;95:e5745.

23. Cantor LB, Katz LJ, Cheng JW, Chen E, Tong KB, Peabody JW. Economic evaluation of medication, laser trabeculoplasty and filtering surgeries in treating patients with glaucoma in the US. Curr Med Res Opin. 2008;24:2905-18.

24. Kaplan RI, De Moraes CG, Cioffi GA, Al-Aswad LA, Blumberg DM. Comparative Cost-effectiveness of the Baerveldt implant, trabeculectomy with mitomycin, and medical treatment. JAMA Ophthalmol. 2015;133:560-7.

25. Berdahl JP, Khatana AK, Katz LJ, Herndon L, Layton AJ, Yu $\mathrm{TM}$, et al. Cost-comparison of two trabecular micro-bypass stents versus selective laser trabeculoplasty or medications only for intraocular pressure control for patients with open-angle glaucoma. J Med Econ. 2017;20:760-6.

26. Patel V, Ahmed I, Podbielski D, Falvey H, Murray J, Goeree R. Cost-effectiveness analysis of standalone trabecular microbypass stents in patients with mild-to-moderate open-angle glaucoma in Canada. J Med Econ. 2019;22:390-401.

27. Owen CG, Carey IM, De Wilde S, Whincup PH, Wormald R, Cook DG. The epidemiology of medical treatment for glaucoma and ocular hypertension in the United Kingdom: 1994 to 2003. Br J Ophthalmol. 2006;90:861-8.

28. Weinreb RN, Toris CB, Gabelt BT, Lindsey JD, Kaufman PL. Effects of prostaglandins on the aqueous humor outflow pathways. Surv Ophthalmol. 2002;47(Suppl 1):S53-64.

29. Weinreb RN, Kashiwagi K, Kashiwagi F, Tsukahara S, Lindsey JD. Prostaglandins increase matrix metalloproteinase release from human ciliary smooth muscle cells. Investigative Ophthalmol Vis Sci. 1997;38:2772-80.

30. Prum BE, Jr., Rosenberg LF, Gedde SJ, Mansberger SL, Stein JD, Moroi SE, et al. Primary open-angle glaucoma preferred practice pattern $((\mathrm{R}))$ guidelines. Ophthalmology. 2016;123: P41-111.

31. Li T, Lindsley K, Rouse B, Hong H, Shi Q, Friedman DS, et al. Comparative effectiveness of first-line medications for primary open-angle glaucoma: a systematic review and network metaanalysis. Ophthalmology. 2016;123:129-40.

32. Grierson I, Pfeiffer N, Cracknell KP, Appleton P. Histology and fine structure of the iris and outflow system following latanoprost therapy. Surv Ophthalmol. 2002;47(Suppl 1):S176-84.

33. Kirwan JF, Nightingale JA, Bunce C, Wormald R. Beta blockers for glaucoma and excess risk of airways obstruction: population based cohort study. BMJ (Clin Res ed). 2002;325:1396-7.

34. Toris CB, Camras CB, Yablonski ME. Acute versus chronic effects of brimonidine on aqueous humor dynamics in ocular hypertensive patients. Am J Ophthalmol. 1999;128:8-14.

35. Schmier JK, Hulme-Lowe CK, Covert DW. Adjunctive therapy patterns in glaucoma patients using prostaglandin analogs. Clinical ophthalmology (Auckland, NZ). 2014;8:1097-104.

36. Higginbotham EJ. Considerations in glaucoma therapy: fixed combinations versus their component medications. Clin Ophthalmol (Auckland, NZ). 2010;4:1-9.

37. Webers CA, Beckers HJ, Zeegers MP, Nuijts RM, Hendrikse F, Schouten JS. The intraocular pressure-lowering effect of prostaglandin analogs combined with topical beta-blocker therapy: a systematic review and meta-analysis. Ophthalmology. 2010;117:2067-74.e1-6.

38. Robin AL, Novack GD, Covert DW, Crockett RS, Marcic TS. Adherence in glaucoma: objective measurements of once-daily and adjunctive medication use. Am J Ophthalmol. 2007;144:533-40.

39. Tsai JC. A comprehensive perspective on patient adherence to topical glaucoma therapy. Ophthalmology. 2009;116(11 Suppl): S30-6.

40. Tsai JC, McClure CA, Ramos SE, Schlundt DG, Pichert JW. Compliance barriers in glaucoma: a systematic classification. J Glaucoma. 2003;12:393-8.

41. Tsai JC. Medication adherence in glaucoma: approaches for optimizing patient compliance. Curr Opin Ophthalmol. 2006;17:190-5.

42. Nordstrom BL, Friedman DS, Mozaffari E, Quigley HA, Walker AM. Persistence and adherence with topical glaucoma therapy. Am J Ophthalmol. 2005;140:598-606.

43. Balkrishnan R, Bond JB, Byerly WG, Camacho FT, Anderson RT. Medication-related predictors of health-related quality of life in glaucoma patients enrolled in a medicare health maintenance organization. Am J Geriatr Pharmacother. 2003;1:75-81.

44. Rahman MQ, Montgomery DM, Lazaridou MN. Surveillance of glaucoma medical therapy in a Glasgow teaching hospital: 26 years' experience. Br J Ophthalmol. 2009;93:1572-5.

45. Broadway D, Grierson I, Hitchings R. Adverse effects of topical antiglaucomatous medications on the conjunctiva. $\mathrm{Br} \mathrm{J}$ Ophthalmol. 1993;77:590-6.

46. Broadway DC, Grierson I, O'Brien C, Hitchings RA. Adverse effects of topical antiglaucoma medication. II. The outcome of filtration surgery. Arch Ophthalmol (Chic, Ill: 1960). 1994;112:1446-54.

47. Li G, Torrejon KY, Unser AM, Ahmed F, Navarro ID, Baumgartner RA, et al. trabodenoson, an adenosine mimetic with a1 receptor selectivity lowers intraocular pressure by increasing conventional outflow facility in mice. Investigative Ophthalmol Vis Sci. 2018;59:383-92.

48. Myers JS, Sall KN, DuBiner H, Slomowitz N, McVicar W, Rich $\mathrm{CC}$, et al. A Dose-escalation study to evaluate the safety, tolerability, pharmacokinetics, and efficacy of 2 and 4 weeks of twice-daily ocular trabodenoson in adults with ocular hypertension or primary open-angle glaucoma. J Ocul Pharmacol Therapeutics: Off J Assoc Ocul Pharmacol Therapeutics. 2016;32: 555-62.

49. Liebmann JM, Lee JK. Current therapeutic options and treatments in development for the management of primary open- 
angle glaucoma. Am J Managed Care. 2017;23(15 Suppl): S279-s92.

50. Ren R, Li G, Le TD, Kopczynski C, Stamer WD, Gong H. Netarsudil increases outflow facility in human eyes through multiple mechanisms. Investigative Ophthalmol Vis Sci. 2016;57:6197-209.

51. Wang RF, Williamson JE, Kopczynski C, Serle JB. Effect of $0.04 \%$ AR-13324, a ROCK, and norepinephrine transporter inhibitor, on aqueous humor dynamics in normotensive monkey eyes. J Glaucoma. 2015;24:51-4.

52. Kiel JW, Kopczynski CC. Effect of AR-13324 on episcleral venous pressure in Dutch belted rabbits. J Ocul Pharmacol Therapeutics : Off J Assoc Ocul Pharmacol Therapeutics. 2015;31:146-51.

53. Serle JB, Katz LJ, McLaurin E, Heah T, Ramirez-Davis N, Usner DW, et al. Two phase 3 clinical trials comparing the safety and efficacy of netarsudil to timolol in patients with elevated intraocular pressure: rho kinase elevated iop treatment trial 1 and 2 (ROCKET-1 and ROCKET-2). Am J Ophthalmol. 2018;186:116-27.

54. Lewis RA, Levy B, Ramirez N, Kopczynski CC, Usner DW, Novack GD. Fixed-dose combination of AR-13324 and latanoprost: a double-masked, 28-day, randomised, controlled study in patients with open-angle glaucoma or ocular hypertension. Br J Ophthalmol. 2016;100:339-44.

55. Garcia GA, Ngai P, Mosaed S, Lin KY. Critical evaluation of latanoprostene bunod in the treatment of glaucoma. Clin Ophthalmol (Auckland, NZ). 2016;10:2035-50.

56. Cavet ME, Vittitow JL, Impagnatiello F, Ongini E, Bastia E. Nitric oxide (NO): an emerging target for the treatment of glaucoma. Investigative Ophthalmol Vis Sci. 2014;55:5005-15.

57. Weinreb RN, Scassellati Sforzolini B, Vittitow J, Liebmann J. Latanoprostene bunod $0.024 \%$ versus timolol maleate $0.5 \%$ in subjects with open-angle glaucoma or ocular hypertension: the APOLLO study. Ophthalmology. 2016;123:965-73.

58. Medeiros FA, Martin KR, Peace J, Scassellati Sforzolini B, Vittitow JL, Weinreb RN. Comparison of latanoprostene bunod $0.024 \%$ and TiMolol Maleate $0.5 \%$ in open-angle glaucoma or ocular hypertension: the LUNAR study. Am J Ophthalmol. 2016;168:250-9.

59. Kawase K, Vittitow JL, Weinreb RN, Araie M. Long-term safety and efficacy of latanoprostene bunod $0.024 \%$ in Japanese subjects with open-angle glaucoma or ocular hypertension: the JUPITER study. Adv Ther. 2016;33:1612-27.

60. Wise JB, Witter SL. Argon laser therapy for open-angle glaucoma. A pilot study. Arch Ophthalmol (Chic, Ill : 1960). 1979;97:319-22.

61. Thomas JV, Simmons RJ, Belcher CD 3rd. Argon laser trabeculoplasty in the presurgical glaucoma patient. Ophthalmology. 1982;89:187-97.

62. Brubaker RF, Liesegang TJ. Effect of trabecular photocoagulation on the aqueous humor dynamics of the human eye. Am $\mathbf{J}$ Ophthalmol. 1983;96:139-47.

63. Latina MA, Park C. Selective targeting of trabecular meshwork cells: in vitro studies of pulsed and CW laser interactions. Exp Eye Res. 1995;60:359-71.

64. Beltran-Agullo L, Alaghband P, Obi A, Husain R, Lim KS. The effect of selective laser trabeculoplasty on aqueous humor dynamics in patients with ocular hypertension and primary openangle glaucoma. J Glaucoma. 2013;22:746-9.

65. Goyal S, Beltran-Agullo L, Rashid S, Shah SP, Nath R, Obi A, et al. Effect of primary selective laser trabeculoplasty on tonographic outflow facility: a randomised clinical trial. $\mathrm{Br} \mathrm{J}$ Ophthalmol. 2010;94:1443-7.

66. Gulati V, Fan S, Gardner BJ, Havens SJ, Schaaf MT, Neely DG, et al. Mechanism of action of selective laser trabeculoplasty and predictors of response. Investigative Ophthalmol Vis Sci. 2017;58:1462-8.

67. Bradley JM, Anderssohn AM, Colvis CM, Parshley DE, Zhu $\mathrm{XH}$, Ruddat MS, et al. Mediation of laser trabeculoplastyinduced matrix metalloproteinase expression by IL-1beta and TNFalpha. Investigative Ophthalmol Vis Sci. 2000;41:422-30.

68. Lee JY, Kagan DB, Roumeliotis G, Liu H, Hutnik CM. Secretion of matrix metalloproteinase- 3 by co-cultured pigmented and non-pigmented human trabecular meshwork cells following selective laser trabeculoplasty. Clin Exp Ophthalmol. 2016; 44:33-42.

69. Izzotti A, Longobardi M, Cartiglia C, Rathschuler F, Sacca SC. Trabecular meshwork gene expression after selective laser trabeculoplasty. PLoS ONE. 2011;6:e20110.

70. Alvarado JA, Katz LJ, Trivedi S, Shifera AS. Monocyte modulation of aqueous outflow and recruitment to the trabecular meshwork following selective laser trabeculoplasty. Arch Ophthalmol (Chic, Ill : 1960). 2010;128:731-7.

71. Kramer TR, Noecker RJ. Comparison of the morphologic changes after selective laser trabeculoplasty and argon laser trabeculoplasty in human eye bank eyes. Ophthalmology. 2001;108:773-9.

72. Arora KS, Robin AL, Corcoran KJ, Corcoran SL, Ramulu PY. Use of various glaucoma surgeries and procedures in medicare beneficiaries from 1994 to 2012. Ophthalmology. 2015;122:1615-24

73. Melamed S, Ben Simon GJ, Levkovitch-Verbin H. Selective laser trabeculoplasty as primary treatment for open-angle glaucoma: a prospective, nonrandomized pilot study. Arch Ophthalmol (Chic, Ill : 1960). 2003;121:957-60.

74. Nagar M, Ogunyomade A, O'Brart DP, Howes F, Marshall J. A randomised, prospective study comparing selective laser trabeculoplasty with latanoprost for the control of intraocular pressure in ocular hypertension and open angle glaucoma. $\mathrm{Br} \mathrm{J}$ Ophthalmol. 2005;89:1413-7.

75. McIlraith I, Strasfeld M, Colev G, Hutnik CM. Selective laser trabeculoplasty as initial and adjunctive treatment for open-angle glaucoma. J Glaucoma. 2006;15:124-30.

76. Katz LJ, Steinmann WC, Kabir A, Molineaux J, Wizov SS, Marcellino G. Selective laser trabeculoplasty versus medical therapy as initial treatment of glaucoma: a prospective, randomized trial. J Glaucoma. 2012;21:460-8.

77. Weinand FS, Althen F. Long-term clinical results of selective laser trabeculoplasty in the treatment of primary open angle glaucoma. Eur J Ophthalmol. 2006;16:100-4.

78. Woo DM, Healey PR, Graham SL, Goldberg I. Intraocular pressure-lowering medications and long-term outcomes of selective laser trabeculoplasty. Clin Exp Ophthalmol. 2015;43:320-7.

79. McAlinden C. Selective laser trabeculoplasty (SLT) vs. other treatment modalities for glaucoma: systematic review. Eye (Lond, Engl). 2014;28:249-58.

80. Nagar M, Luhishi E, Shah N. Intraocular pressure control and fluctuation: the effect of treatment with selective laser trabeculoplasty. Br J Ophthalmol. 2009;93:497-501.

81. Li X, Wang W, Zhang X. Meta-analysis of selective laser trabeculoplasty versus topical medication in the treatment of openangle glaucoma. BMC Ophthalmol. 2015;15:107.

82. Ayala M. Intraocular pressure reduction after initial failure of selective laser trabeculoplasty (SLT). Graefe's Arch Clin Exp Ophthalmol=Albrecht von Graefes Arch fur klinische und experimentelle Ophthalmologie. 2014;252:315-20.

83. Francis BA, Loewen N, Hong B, Dustin L, Kaplowitz K, Kinast $\mathrm{R}$, et al. Repeatability of selective laser trabeculoplasty for openangle glaucoma. BMC Ophthalmol. 2016;16:128. 
84. Hong BK, Winer JC, Martone JF, Wand M, Altman B, Shields B. Repeat selective laser trabeculoplasty. J Glaucoma. 2009;18:180-3.

85. Polat J, Grantham L, Mitchell K, Realini T. Repeatability of selective laser trabeculoplasty. Br J Ophthalmol. 2016; 100:1437-41.

86. Khouri AS, Lin J, Berezina TL, Maltzman B, Fechtner RD. Repeat selective laser trabeculoplasty can be effective in eyes with initial modest response. Middle East Afr J Ophthalmol. 2014;21:205-9.

87. Khouri AS, Lari HB, Berezina TL, Maltzman B, Fechtner RD. Long term efficacy of repeat selective laser trabeculoplasty. J ophthalmic Vis Res. 2014;9:444-8.

88. Avery N, Ang GS, Nicholas S, Wells A. Repeatability of primary selective laser trabeculoplasty in patients with primary openangle glaucoma. Int Ophthalmol. 2013;33:501-6.

89. Song J. Complications of selective laser trabeculoplasty: a review. Clin Ophthalmol (Auckland, NZ). 2016;10:137-43.

90. Kennedy JB, SooHoo JR, Kahook MY, Seibold LK. Selective laser trabeculoplasty: an update. Asia-Pacific J Ophthalmol (Philadelphia, Pa). 2016;5:63-9.

91. White AJ, Mukherjee A, Hanspal I, Sarkies NJ, Martin KR, Shah P. Acute transient corneal endothelial changes following selective laser trabeculoplasty. Clin Exp Ophthalmol. 2013;41:435-41.

92. Regina M, Bunya VY, Orlin SE, Ansari H. Corneal edema and haze after selective laser trabeculoplasty. J Glaucoma. 2011;20:327-9.

93. Ha JH, Bowling B, Chen SD. Cystoid macular oedema following selective laser trabeculoplasty in a diabetic patient. Clin Exp Ophthalmol. 2014;42:200-1.

94. Wechsler DZ, Wechsler IB. Cystoid macular oedema after selective laser trabeculoplasty. Eye (Lond, Engl). 2010;24:1113.

95. Wu ZQ, Huang J, Sadda S. Selective laser trabeculoplasty complicated by cystoid macular edema: report of two cases. Eye Sci. 2012;27:193-7.

96. Phillis CA, Bourke RD. Bilateral subretinal fluid mimicking subretinal neovascularization within 24 hours after selective laser trabeculoplasty. J Glaucoma. 2016;25:e110-4.

97. Kim DY, Singh A. Severe iritis and choroidal effusion following selective laser trabeculoplasty. Ophthalmic Surg, lasers Imaging : Off J Int Soc Imaging Eye. 2008;39:409-11.

98. Hernandez Pardines F, Molina Martin JC, Fernandez Montalvo L, Aguirre Balsalobre F. Bilateral choroidal effusion after selective laser trabeculoplasty. Archivos de la Sociedad Espanola de. Oftalmologia. 2017;92:295-8.

99. Wong MO, Lee JW, Choy BN, Chan JC, Lai JS. Systematic review and meta-analysis on the efficacy of selective laser trabeculoplasty in open-angle glaucoma. Surv Ophthalmol. 2015;60:36-50.

100. Baser EF, Akbulut D. Significant peripheral anterior synechiae after repeat selective laser trabeculoplasty. Can J Ophthalmol J canadien d'ophtalmologie. 2015;50:e36-8.

101. Bovell AM, Damji KF, Hodge WG, Rock WJ, Buhrmann RR, Pan YI. Long term effects on the lowering of intraocular pressure: selective laser or argon laser trabeculoplasty? Can J Ophthalmol J Canadien d'ophtalmologie. 2011;46:408-13.

102. Rolim de Moura C, Paranhos A, Jr., Wormald R. Laser trabeculoplasty for open angle glaucoma. Cochrane Database Syst Rev. 2007: Cd003919.

103. Ekici F, Waisbourd M, Katz LJ. Current and future of laser therapy in the management of glaucoma open. Ophthalmol J. 2016;10:56-67.

104. Rantala E, Valimaki J. Micropulse diode laser trabeculoplasty180-degree treatment. Acta Ophthalmologica. 2012;90:441-4.

105. Fea AM, Bosone A, Rolle T, Brogliatti B, Grignolo FM. Micropulse diode laser trabeculoplasty (MDLT): A phase II clinical study with 12 months follow-up. Clin Ophthalmol (Auckland, NZ). 2008;2:247-52.

106. Lee JW, Yau GS, Yick DW, Yuen CY. Micropulse laser trabeculoplasty for the treatment of open-angle glaucoma. Medicine. 2015;94:e2075.

107. Abramowitz B, Chadha N, Kouchouk A, Alhabshan R, Belyea DA, Lamba T. Selective laser trabeculoplasty vs. micropulse laser trabeculoplasty in open-angle glaucoma. Clin Ophthalmol (Auckland, NZ). 2018;12:1599-604.

108. Goldenfeld M, Melamed S, Simon G, Ben Simon GJ. Titanium: sapphire laser trabeculoplasty versus argon laser trabeculoplasty in patients with open-angle glaucoma. Ophthalmic Surg, lasers Imaging : Off J Int Soc Imaging Eye. 2009;40:264-9.

109. Kaplowitz K, Wang S, Bilonick R, Oatts JT, Grippo T, Loewen NA. Randomized controlled comparison of titanium-sapphire versus standard Q-switched Nd: YAG laser trabeculoplasty. J Glaucoma. 2016;25:e663-7.

110. Mansouri K, Shaarawy T. Comparing pattern scanning laser trabeculoplasty to selective laser trabeculoplasty: a randomized controlled trial. Acta Ophthalmologica. 2017;95:e361-e5.

111. Belkin M, Geffen N, Ofir S, Kaplan Messas A, Barkana Y, Belkin A, et al. Direct trans-scleral selective laser trabeculoplasty (SLT) without a gonioscopy lens. Investigative Ophthalmol Vis Sci. 2014;55:819.

112. Geffen N, Ofir S, Belkin A, Segev F, Barkana Y, Kaplan Messas A, et al. Transscleral selective laser trabeculoplasty without a gonioscopy lens. J Glaucoma. 2017;26:201-7.

113. Zhang ML, Hirunyachote P, Jampel H. Combined surgery versus cataract surgery alone for eyes with cataract and glaucoma. Cochrane Database Syst Rev. 2015: Cd008671.

114. Burr J, Azuara-Blanco A, Avenell A, Tuulonen A. Medical versus surgical interventions for open angle glaucoma. Cochrane Database Syst Rev. 2012:Cd004399.

115. King AJ, Fernie G, Azuara-Blanco A, Burr JM, Garway-Heath T, Sparrow JM, et al. Treatment of advanced glaucoma study: a multicentre randomised controlled trial comparing primary medical treatment with primary trabeculectomy for people with newly diagnosed advanced glaucoma-study protocol. Br J Ophthalmol. 2018;102:922-8.

116. Watson PG, Barnett F. Effectiveness of trabeculectomy in glaucoma. Am J Ophthalmol. 1975;79:831-45.

117. Gedde SJ, Schiffman JC, Feuer WJ, Herndon LW, Brandt JD, Budenz DL. Treatment outcomes in the tube versus trabeculectomy (TVT) study after five years of follow-up. Am J Ophthalmol. 2012;153:789-803.e2.

118. Gedde SJ, Feuer WJ, Shi W, Lim KS, Barton K, Goyal S, et al. Treatment outcomes in the primary tube versus trabeculectomy study after 1 year of follow-up. Ophthalmology. 2018;125:650-63.

119. Budenz DL, Barton K, Gedde SJ, Feuer WJ, Schiffman J, Costa VP, et al. Five-Year treatment outcomes in the Ahmed Baerveldt comparison study. Ophthalmology. 2015;122:308-16.

120. O'Brart DPS, Rowlands E, Islam N, Noury AMS. A randomised, prospective study comparing trabeculectomy augmented with antimetabolites with a viscocanalostomy technique for the management of open angle glaucoma uncontrolled by medical therapy. Br J Ophthalmol. 2002;86:748-54.

121. Gilmour DF, Manners TD, Devonport H, Varga Z, Solebo AL, Miles J. Viscocanalostomy versus trabeculectomy for primary open angle glaucoma: 4-year prospective randomized clinical trial. Eye (Lond, Engl). 2009;23:1802-7.

122. Jonescu-Cuypers C, Jacobi P, Konen W, Krieglstein G. Primary viscocanalostomy versus trabeculectomy in white patients with open-angle glaucoma: a randomized clinical trial. Ophthalmology. 2001;108:254-8.

123. Samuelson TW, Sarkisian SR Jr., Lubeck DM, Stiles MC, Duh YJ, Romo EA, et al. Prospective, randomized, controlled pivotal 
trial of an $\mathrm{Ab}$ interno implanted trabecular micro-bypass in primary open-angle glaucoma and cataract: two-year results. Ophthalmology. 2019;126:811-21.

124. Samuelson TW, Chang DF, Marquis R, Flowers B, Lim KS, Ahmed IIK, et al. A Schlemm canal microstent for intraocular pressure reduction in primary open-angle glaucoma and cataract: The HORIZON Study. Ophthalmology. 2019;126:29-37.

125. Vold S, Ahmed II, Craven ER, Mattox C, Stamper R, Packer M, et al. Two-Year COMPASS trial results: supraciliary microstenting with phacoemulsification in patients with open-angle glaucoma and cataracts. Ophthalmology. 2016;123:2103-12.

126. Chatzara A, Chronopoulou I, Theodossiadis G, Theodossiadis $P$, Chatziralli I. XEN implant for glaucoma treatment: a review of the literature. Semin Ophthalmol. 2019;34:93-7.

127. Brandao LM, Grieshaber MC. Update on minimally invasive glaucomasurgery (MIGS) and new implants. J Ophthalmol. 2013;2013:705915.
128. Almasieh M, Levin LA. Neuroprotection in glaucoma: animal models and clinical trials. Annu Rev Vis Sci. 2017; 3:91-120.

129. Levin LA, Danesh-Meyer HV. Lost in translation: bumps in the road between bench and bedside. JAMA. 2010;303:1533-4.

130. Prum BE Jr., Lim MC, Mansberger SL, Stein JD, Moroi SE, Gedde SJ, et al. Primary open-angle glaucoma suspect preferred practice pattern((R)) guidelines. Ophthalmology. 2016;123:P112-51.

131. NICE. National Institute for Health and Clinical Excellence. NICE: Guidance on Glaucoma: Diagnosis and management of chronic open angle glaucoma and ocular hypertension: DoH; 2010. www.nice.org.uk/CG85fullguideline. 2010.

132. European Glaucoma Society Terminology and Guidelines for Glaucoma, 4th edn-Chapter 3: Treatment principles and options Supported by the EGS Foundation: Part 1: Foreword; Introduction; Glossary; Chapter 3 Treatment principles and options. Br J Ophthalmol. 2017;101:130-95. 